\title{
Healing of cervical epithelium after laser ablation of cervical intraepithelial neoplasia
}

\author{
GLM SHARP, JW CORDINER, E LESLEY MURRAY, IAR MORE \\ From the University Departments of Midwifery and Pathology, Western Infirmary, Glasgow
}

SUMMARY Healing of cervical epithelium was studied in 30 patients after destruction of cervical intraepithelial neoplasia using a carbon dioxide laser. Repeated examinations, using photography and colposcopically directed punch biopsies, were made from the eighth to the 32nd day after treatment. The biopsy specimens were submitted to examination by light and transmission electron microscopy. There was complete epithelial cover of the laser induced craters in all patients by 28 days. The base of the crater and endocervical edge became covered by columnar epithelial cells originating in endocervical crypts, while the vaginal edge re-epithelialised by an ingrowth of the surrounding squamous epithelium. Squamous metaplasia of the new columnar epithelium was a common observation as early as eight days after treatment. There was no evidence for a stromal contribution to epithelial cover.

The carbon dioxide laser was introduced to gynaecological practice to treat premalignant lesions of the uterine cervix. ${ }^{1-5}$ These lesions, termed cervical intraepithelial neoplasia (CIN) by Richart, ${ }^{\circ}$ affect not only surface squamous epithelium of the transformation zone but also the epithelium that invaginates the underlying stroma as crypts or clefts. Anderson and Hartley ${ }^{7}$ have shown that the crypt involvement rarely extends beyond $4 \mathrm{~mm}$ in women under the age of 40 . It is this group of women who are at risk of developing CIN. These findings would suggest that to treat CIN successfully by laser ablation at least $4 \mathrm{~mm}$ depth of total tissue destruction should be achieved. Sharp et al showed that by achieving a power density of $1415 \mathrm{~W} / \mathrm{cm}^{2}$ for $1 \mathrm{~s}$ the laser would consistently destroy normal cervical tissue to a depth of greater than $5.0 \mathrm{~mm}$. The drill hole technique was conceived and developed using these data.

Many reports on the use of the carbon dioxide laser on the cervix have commented on the subsequent effective and rapid healing. Kaplan et $a l^{9}$ described the average time for healing after laser ablation to cervical ectopy as 13 days, while Bellina and Polanyi ${ }^{10}$ noted healing by day $13-15$ and normal epithelial cover by 21 days. Baggish ${ }^{5}$ described the appearance of an epithelial cover between the 10 th and 21 st day and complete healing was

Accepted for publication 7 March 1984 observed by Stafl $e t$ al and Carter $e t$ al ${ }^{11}$ by four weeks. This contrasts with the use of cryocautery: Townsend $e t \mathrm{al}^{12}$ reported that healing may take as long as eight weeks. The speed of healing and relative lack of vaginal discharge after laser ablation, in contrast to cryocautery and electrocautery, are believed by Bellina ${ }^{2}$ to be due to the minimal necrosis associated with laser destruction.

The present study was undertaken to confirm the rapidity of healing of the cervix after laser ablation, to evaluate the contribution made by squamous and endocervical epithelium to the healing process, and to establish evidence, or otherwise, of a stromal contribution to the epithelial cover.

\section{Patients and methods}

All patients who took part in the study had previously undergone colposcopic assessment. A diagnosis of CIN had been confirmed after histological examination of colposcopically directed punch biopsies in each case. Informed consent for repeated colposcopic assessment and biopsy was obtained from all patients.

On attendance at the laser clinic colposcopy was repeated, the transformation zone identified, and its extent confirmed. The whole transformation zone was treated with the carbon dioxide laser (Coherent 450). Laser drill holes were placed on the cervix using the method of Sharp et al. ${ }^{8}$ This achieved a uniform depth of at least $5 \mathrm{~mm}$. The laser wound 
was completed using the continuous mode, thus vaporising a cylindrical cross section of tissue of standard depth.

The patients were advised to avoid coitus and the use of tampons for one month after treatment. No patient was seen earlier than eight days after treatment as work by Bellina et al $^{13}$ had shown that only cells participating in the acute inflammatory response to the tissue injury were present before this time. At follow up visits each patient underwent colposcopic assessment. The cervix was observed and photographed, this being supplemented by directed punch biopsy of the new epithelial cover from the base and edge of the laser wound using Leech-Wilkinson forceps. The positions of the biopsy sites were recorded diagrammatically. Care was taken at each examination to avoid biopsy from the site of a previous biopsy, both from laser crater base and edge.

The biopsy specimens were divided: one half was fixed in neutral buffered formalin, the tissue embedded in paraffin wax, sectioned, and subsequently stained with haematoxylin and eosin for light microscopic examination. The other half of the biopsy was fixed in $2.5 \%$ phosphate buffered glutaraldehyde, postfixed in osmium tetroxide, and embedded in Araldite. Sections were cut on an LKB Ultratome III, double stained with uranyl acetate and lead citrate, and viewed in a Philips EM 301G electron microscope.

After completion of the study all patients were reviewed at the colposcopy clinic at four and 12 months after treatment.

\section{Results}

The Table gives details of patient attendances at various times after laser treatment. By day 8 the

\section{Details of patient attendances and number of biopsies}

No of days after laser

treatment

No of patients

Base biopsies

Edge biopsies

\begin{tabular}{rlllll}
8 & $11-12$ & $15-16$ & $18-22$ & $24-28$ & $29-32$ \\
13 & 14 & 11 & 22 & 12 & 7 \\
13 & 13 & 10 & 18 & 9 & 4 \\
13 & 14 & 10 & 19 & 12 & 7 \\
\hline
\end{tabular}

cervix was covered with a grey/yellow slough and carbon ash was still abundantly present. Even at this early stage light microscopy of crater base biopsy samples showed evidence of re-epithelialisation. The epithelial cells were plump, almost cuboidal in appearance. Mitotic figures were often seen in the covering epithelium, which was always in continuity with the columnar epithelium of the endocervical crypts (Fig. 1). Transmission electron microscopy of these cells confirmed their nature. The nuclei contained prominent nucleoli. Desmosomes were inconspicuous at cell borders and there were numerous surface villi. There were large numbers of intracytoplasmic secretory granules and substantial quantities of rough endoplasmic reticulum, consistent with young mucus secreting cells (Fig. 2).

Colposcopy on day 12 showed evidence of epithelial cover originating from the squamous epithelium at the vaginal edge of the crater. This was confirmed by light and electron microscopy. The latter examination showed that the nuclei, most of which contained nucleoli, were active, with diffuse nuclear chromatin. Tonofibrils and intracellular keratohyaline granules were often seen. This indicated that the cells had the ultrastructural characteristics of immature squamous epithelial cells (Fig. 3).

By day 22, the epithelial squamous edge had continued to advance slowly, but most of the surface epithelial cover originated from coalescing foci or islands of epithelium which had grown out from

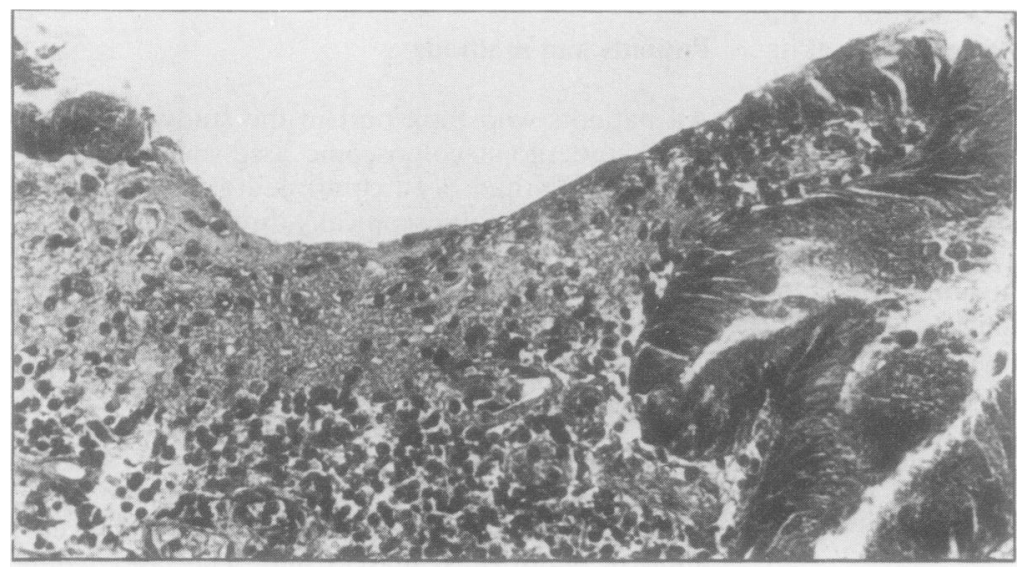

Fig. 1 Biopsy sample from base of ulcer 12 days after laser treatment. Note cells from the mucin secreting gland spreading over the ulcer base. Haematoxylin and eosin. Original magnification $\times 310$. 


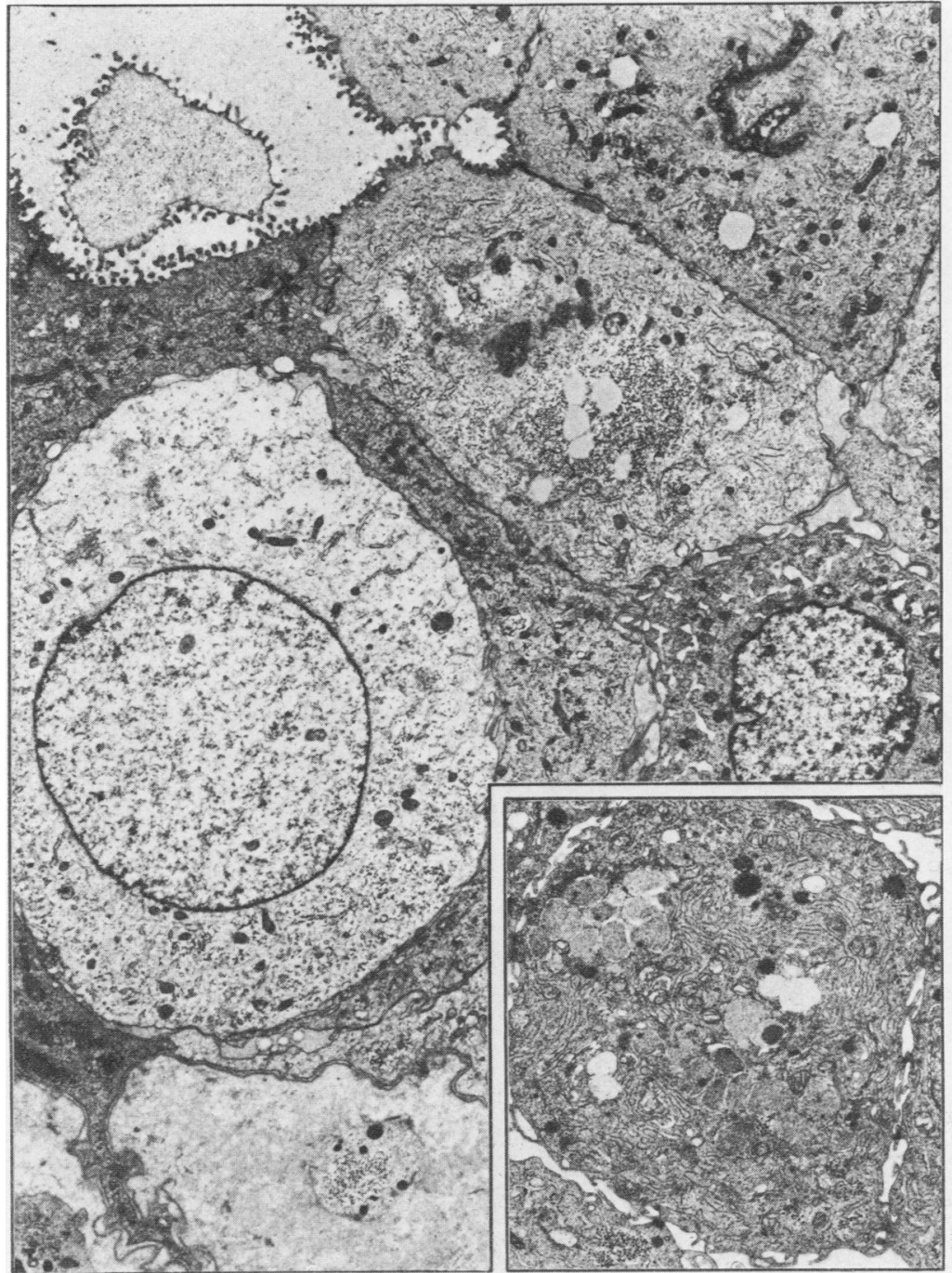

Fig. 2 Biopsy sample from base of ulcer 12 days after laser treatment. Mucin secreting epithelium. Original magnification $\times 6300$. Oedematous epithelium showing immature low columnar cells with apical microvilli. The cells contain active nuclei, glycogen, and small mitochondria. Inset (original magnification $\times 9675$ ): more mature mucus secreting epithelium containing abundant rough endoplasmic reticulum and discrete mucin droplets.

endocervical crypts. Even at day 22, epithelialisation could be incomplete and areas of slough could still be present. Epithelial cover was complete by day 28 in every case.

At the four month review cervical cytology and colposcopy were normal in 29 of the 30 patients. One patient, whose original lesion was CIN III, subsequently underwent colposcopically directed cone biopsy for residual CIN II. A second patient, in whom the original lesion was CIN III, with negative cytology and colposcopy findings four months after laser, was pregnant on review 12 months after treatment. The new transformation zone was normal on colposcopic examination, but occasional dyskaryotic cells were reported on cytology. The pregnancy proceeded uneventfully to term and resulted in a spontaneous vertex delivery. Three months post partum, colposcopy revealed a metaplastic transformation zone, but cervical cytology was now negative. 


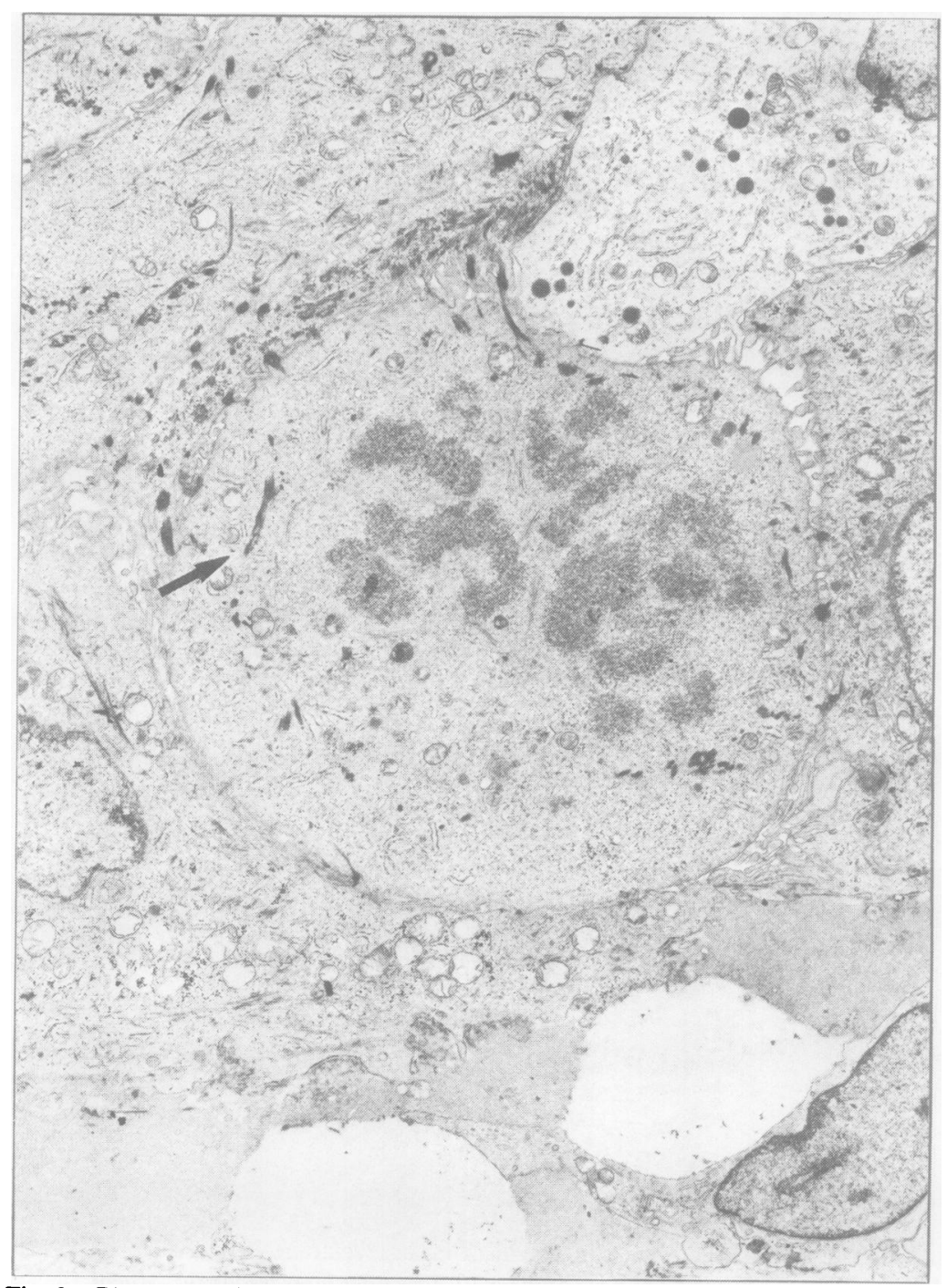

Fig. 3 Biopsy sample from edge of ulcer 12 days after laser treatment. Squamous epithelium. Original magnification $\times 8100$. Actively growing plump squamous cells with evidence of mitotic activity. Note the presence of tonofilaments (arrow) and desmosomes. The cell surface is active and glycogen is apparent in the cytoplasm.

\section{Discussion}

The timing of the appearance and characteristics of the regenerating cervical epithelium in this study are consistent with the observations of other workers. Stafl $e t a^{1}$ found that the treated area on the cervix was completely healed one month after laser ablation. Carter et al $^{11}$ examined 45 patients by means of colposcopy four weeks after treatment for CIN and showed that the cervix had healed with complete epithelial cover. Holmquist et al $^{14}$ used exfoliative cytology taken daily between one and 21 days after laser treatment to show that by three weeks normal epithelium and cytological appearances could be noted.

Bellina and Seto, ${ }^{15}$ using scanning electron microscopy, observed cells with the characteristic features of squamous epithelium on the 10th day after laser ablation to the cervix. Mylotte et al ${ }^{16}$ found squamous cells covering the laser wound by day 11 , and Baggish" noted a "cloudy veil of squamous metaplasia" at colposcopy 10 days after laser treat- 
ment. He described the laser wound as being fully covered by "young squamous cells" at 14 days after treatment. No attempts were made in the latter study to biopsy the new epithelium.

The present study found no evidence of a stromal contribution to epithelial healing. This contrasts with the work of Reid et al, ${ }^{17}$ who used electrocautery to cause a cervical lesion $5 \mathrm{~mm}$ in depth and then followed tissue regeneration with light microscopy and colposcopy. They considered most of the cells forming the new epithelium were derived from blood borne mononuclear cells, which secreted a periodic acid Schiff positive substance at their periphery. The authors interpreted this as basement membrane material, but ultrastructural examination of these cells was not carried out. Lawrence and Shingleton ${ }^{18}$ were unable to confirm these findings. Using both light and transmission electron microscopy to study cervical metaplasia, they described the presence of subepithelial stroma cells which had the same characteristics of epithelial cells-namely, the presence of hemidesmosome like structures scattered around the periphery of the cells and fine fibrillar components which connected the cell membrane and basal lamina. They emphasised that these features were not commonly associated with stromal fibroblasts, nor wandering tissue macrophages. They were unable to find any instance of such cells having migrated through the basement membranes. In adiition, bundles of tonofibrils, a distinguishing feature of cervical squamous cells, were never seen in these cells. Two earlier studies, those of Bellina et $a l^{13}$ and Dorsey and Diggs, ${ }^{19}$ were unable to find evidence of stromal transformation during reepithelialisation after laser ablation.

This present study is the first to report the use of both light and transmission electron microscopy after laser ablation to CIN. The most striking observation was that the base of the laser wound was covered by columnar cells originating in the endocervical crypts. In none of the specimens examined was there any break in continuity between the crypt and regenerating surface epithelium. No piece of epithelium was seen to be an isolated island although examination at several levels of the base biopsy was often necessary to confirm this.

A major theoretical concern is that healing after laser may bury CIN in crypts. Sevin $e a^{20}$ reported this after cervical cryocautery for CIN with subsequent development of invasive squamous cell carcinoma beneath a healed normal surface epithelium. From the present study, it was important to find that residual crypt epithelium contributed to healing after laser ablation and that any residual abnormal cells regenerating from residual CIN remaining in untreated crypts would subsequently appear on the new epithelial surface.
We acknowledge the assistance given by members of the Electron Microscopy Unit, Department of Pathology, Western Infirmary.

GLMS was supported by a Scottish Hospital Endowment Research Trust grant no 571.

\section{References}

' Staf A, Wilkinson EJ, Mattingly RF. Laser treatment of cervical and vaginal neoplasia. Am J Obstet Gynecol 1977;128:12836.

${ }^{2}$ Bellina J. Carbon dioxide laser in gynaecology. Ann Obstet Gynecol 1977;6:371-91.

${ }^{3}$ Jordan JA. Laser treatment of cervical intraepithelial neoplasia. Obstet Gynecol Surv 1979;34:831.

4 Masterton BJ, Krantz KE, Calkins JW, Magrina JF, Carter RP. The carbon dioxide laser in cervical intraepithelial neoplasia: a five year experience in treating 230 patients. Am J Obstet Gynecol 1981;139:565-7.

5 Baggish MS. High power carbon dioxide laser therapy for early cervical neoplasia. Am J Obstet Gynecol 1980;136:117-25.

- Richart RM. Influences of diagnostic and therapeutic procedures on the distribution of cervical intraepithelial neoplasia. Cancer 1966;19:1635-8.

7 Anderson MC, Hartley RB. Cervical crypt involvement by intraepithelial neoplasia. Obstet Gynecol 1980;55:546-50.

${ }^{8}$ Sharp F, MacLean AM, More IAR, Murray EM. Quantitated laser tissue destruction and the development of a technique for treating cervical intraepithelial neoplasia. In: Bellina JH, ed. Gynecologic laser surgery. New York and London: Plenum Press. 1981:231-44.

' Kaplan I, Goldman J, Ger R. The treatment of the uterine cervix by means of the carbon dioxide laser. Obstet Gynecol 1973;41:795-6.

${ }^{10}$ Bellina JH, Polanyi TG. Management of vaginal adenosis and related cervico-vaginal disorders in DES exposed progeny by means of carbon dioxide laser surgery. J Reprod Med 1976;16:295-6.

" Carter R, Krantz KE, Hara GS, Lin F, Masterton BJ, Smith SJ. Treatment of cervical intraepithelial neoplasia with the carbon dioxide laser beam. Am J Obstet Gynecol 1978;131:831-6.

12 Townsend DE, Ostergard DR. Cryocauterisation for preinvasive cervical neoplasia. J Reprod Med 1971;6:171-6.

${ }^{13}$ Bellina JH, Voros JI, Kurpel JE. Carbon dioxide laser microsurgery in gynaecology. Int Adv Surg Oncol 1978;1:227-36.

14 Holmquist ND, Bellina JH, Danos MC. Vaginal and cytological changes following laser treatment. Acta Cytol 1976;29:290-4.

${ }^{15}$ Bellina JH, Seto YJ. Pathological and physical investigations into $\mathrm{CO}_{2}$ laser tissue with specific emphasis on cervical intraepithelial neoplasia. Lasers in Surgery and Medicine 1980;1:47-69.

${ }^{16}$ Mylotte MJ, Allen JM, Jordan JA. Regeneration of cervical epithelium following laser destruction of intraepithelial neoplasia. Obstet Gynecol Surv 1979;34:859-60.

17 Reid BL, Singer A, Coppleson M. The process of cervical regeneration after electro-cauterisation. A histochemical, autoradiographic and $\mathrm{pH}$ study. Aust NZ J Obstet Gynecol 1967;7:125-35.

${ }^{18}$ Lawrence WD, Shingleton HM. Early physiologic squamous metaplasia of the cervix: light and electron microscopic observations. Am J Obstet Gynecol 1980;137:661-71.

19 Dorsey JH, Diggs ES. Microsurgical conization of the cervix by carbon dioxide laser. Obstet Gynecol 1979;54:565-70.

${ }^{20}$ Sevin B, Ford JH, Girtanner RD. Hoskins WJ, Averette HE. Invasive cancer of the cervix after cryosurgery. Obstet Gynecol 1979;45:456.

Requests for reprints to: Dr IAR More, Department of Pathology, The Western Infirmary, Glasgow, Scotland. 